\title{
Biocompatibilidade e biodegradabilidade de micropartículas de poli-lactato-co-glicolato na ceratite infecciosa em coelhos
}

\author{
[Biocompatibility and biodegradability of poly-latic-co-glycolatic microparticles in the infectious \\ keratitis in rabbits] \\ J.J.T. Ranzani ${ }^{1}$, T.P. Peixoto ${ }^{2}$, C.V.S. Brandão ${ }^{1}$, A.G. Oliveira ${ }^{3}$, M.L.R.S. Cunha ${ }^{1}$, \\ E.S. Mori ${ }^{4}$ B.W. Minto ${ }^{5^{*}}$ \\ ${ }^{1}$ Faculdade de Medicina Veterinária e Zootecnia - UNESP - Botucatu, SP \\ ${ }^{2}$ Aluno de pós-graduação - Faculdade de Medicina Veterinária e Zootecnia - UNESP - Botucatu, SP \\ ${ }^{3}$ Faculdade de Ciências Farmacêuticas - UNESP - Araraquara, SP \\ ${ }^{4}$ Médico veterinário autônomo \\ ${ }^{5}$ Faculdade de Ciências Agrárias e Agronômicas - UNESP - Jaboticabal, SP
}

\begin{abstract}
RESUMO
Avaliaram-se a biocompatibilidade e a biodegradabilidade do sistema de liberação controlada de polilactato-co-glicolato (PLGA) no tratamento com ciprofloxacina das ceratites por Staphylococcus aureus em coelhos. Foram utilizados 20 coelhos, distribuídos em quatro grupos (G). Os animais dos G1, G3 e G4 foram inoculados com $2,5 \mu \mathrm{L}$ da bactéria $-10^{8} \mathrm{UFC}$, no estroma corneano. Os do G2 não receberam a aplicação do inóculo. O tratamento foi realizado com solução salina básica para os animais do G1, micropartículas de PLGA contendo ciprofloxacina nos animais dos G2 e G4 e colírio de ciprofloxacina naqueles do G3. Suabe e biópsia da superfície ocular foram coletados para cultura. Apenas um animal do G1 apresentou cultura positiva para $S$. aureus. Exame histológico revelou a presença bacteriana em todos os animais do G1 e em dois animais do G3. Também foi constatada reação inflamatória no local da aplicação do sistema de liberação controlada. O tratamento com micropartículas de PLGA foi eficiente no tratamento de ceratites bacterianas, ao eliminar por completo a presença do S. aureus, mas entretanto não foi completamente biocompatível e biodegradável após cinco dias.
\end{abstract}

Palavras-chave: coelho, sistema de liberação controlada, ceratite, poli-lactato-co-glicolato, Staphylococcus aureus

\begin{abstract}
The biocompatibility and biodegradability of the controlled delivery system of Poly-Latic-Co-Glucolatic (PLGA) in the treatment of Staphylococcus aureus keratitis with ciprofloxacin in rabbits were evaluated. Twenty rabbits divided into four groups $(G)$ were used. G1, G3 and G4 animals were inoculated with bacterial $2.5 \mu \mathrm{L}(108 C F U)$ in the corneal stroma, and G2 animals did not receive the application of inoculum. The treatment was performed with basic saline solution in G1 rabbits, micro particles of PLGA containing ciprofloxacin in G2 and G4 animals, and ciprofloxacin eye drops in G3 rabbits. Swab and biopsy of the ocular surface were collected for culture. Only one animal in G1 had positive culture for S. aureus in the processed material. Histological examination showed a bacterial presence in all animals in G1 and two animals in G3. Inflammatory reaction was noted at the application site of the controlled release. Data analysis showed that treatment with micro particles of PLGA was effective in treating bacterial keratitis, completely eliminating the presence of $\mathrm{S}$. aureus, but it was not being completely biocompatible and biodegradable after five days.
\end{abstract}

Keywords: rabbit, controlled delivery system, keratitis, Staphylococcus aureus

Recebido em 30 de junho de 2011

Aceito em 16 de abril de 2012

*Autor para correspondência (corresponding author)

E-mail: brunobtu@yahoo.com.br 


\section{INTRODUÇÃO}

O olho é um órgão virtualmente impermeável à maioria dos agentes ambientais. Vários mecanismos anatomofisiológicos contribuem para a formação de um escudo contra agressões à esfera e circulação ocular. As ceratites bacterianas são consideradas uma das afecções oculares mais graves, pois podem resultar em perda parcial ou total da acuidade visual. Como a maioria dos patógenos não consegue penetrar na córnea intacta, infecções corneanas derivam essencialmente da falha nos mecanismos de defesa que mantém a sua superfície íntegra (Dowling e Grahn, 1998; Gelatt, 2000; Ghelardi, 2004; McGhee e Niederer, 2006; Pontes et al., 2008).

O principal objetivo da terapêutica ocular é atingir concentrações farmacológicas suficientemente altas no tecido-alvo sem causar danos tóxicos (Gelatt, 2000). A capacidade de uma droga em não causar danos tóxicos ou lesões a um sistema biológico é conhecida como biocampatibilidade. A avaliação da biocompatibilidade de implantes requer o conhecimento das características inflamatórias e cicatriciais provocadas por estes materiais. Inflamação, cicatrização e reação a corpos estranhos são consideradas respostas tecidual ou celular às lesões (Anderson e Shive, 1997).

Sistemas de liberação poliméricos consistem de polímeros que dispersam o seu conteúdo por difusão ou degradação, prolongando o efeito da droga de uma maneira constante através do tempo (Lima e Júnior, 1999). Os implantes são preparados a partir de diferentes polímeros, podendo ser biodegradáveis ou não biodegradáveis, e divididos em dois tipos (Fialho et al., 2003).

O principal objetivo do microencapsulamento polimérico é o de recobrir o material com um polímero artificial ou natural, biocompatível e biodegradável, que irá proteger e prevenir a rápida degradação e liberar o fármaco (Lima e Júnior, 1999; Bourges et al., 2003; Kompella et al., 2003). Estes polímeros incluem os naturais à base de proteína - albuminas bovina e humana, colágeno e gelatina - e os sintéticos, como as poliamidas, poliaminoácidos, polialquilcianacrilatos, poliésteres, poliortoésteres, poliuretanos, poliacrilamidas e copolímeros. Entre os polímeros disponíveis, o poliéstere poli (D,Llático) (PLA) e o copolímero derivado dos ácidos lático e glicólico (poli-lactato-co-glicolato) (PLGA), são os mais utilizados, pois podem ser sintetizados em vários tamanhos moleculares e conformações, o que permite o encapsulamento de fórmulas específicas (Bourges et al., 2003; Fialho et al., 2003; Kompella et al., 2003).

A degradação do polímero de PLGA ocorre por hidrólise das cadeias terminais. Os produtos resultantes são o lactato e o glicolato, que são inócuos ao organismo e eliminados do corpo pelo ciclo de Krebs. Durante a biodegradação, o material encapsulado é liberado, o que pode levar de horas até meses, dependendo da combinação de polímeros (Lima e Júnior, 1999; Fialho et al., 2003; Kompella et al., 2003).

O presente trabalho teve por objetivos testar os polímeros de PLGA contendo ciprofloxacina e determinar se estes são capazes de manter sua capacidade terapêutica no tratamento de ceratites experimentais causadas por Staphylococcus aureus, com boa biocompatibilidade $\mathrm{e}$ biodegradabilidade.

\section{MATERIAL E MÉTODOS}

A ceratite experimentalmente induzida foi produzida por meio da inoculação de uma linhagem com padrão internacional, S. aureus ATCC 25923, previamente descrita como causadora de ceratite em coelhos e analisada em estudos de tratamento experimental de ceratite bacteriana. $\mathrm{O}$ cultivo bacteriano foi realizado em Laboratório Escola. Para verificação da pureza da amostra, Staphylococcus aureus ATCC 25923 foi semeado em placa de ágar sangue por 24 horas a $37^{\circ} \mathrm{C}$. Para o preparo do inóculo, colônias de $S$. aureus foram semeadas em caldo infusão de cérebro e coração (BHI), e após incubação por 24 horas a $37^{\circ} \mathrm{C}$, a turvação foi ajustada de acordo com a escala 0,5 de McFarland, utilizando-se solução salina $(0,85 \%)$ como diluente. Essa turbidez corresponde aproximadamente a uma contagem de $10^{8} \mathrm{UFC} / \mathrm{mL}$.

O preparo das micropartículas foi realizado em Laboratório Escola. Hidroclorido de ciprofloxacina foi dissolvido em etanol e água, na proporção de 1:1, e adicionado a soluções de polímero em acetona para obter misturas entre 
droga/polímero. As micropartículas foram obtidas pelo processo de spray drying, que consiste basicamente em dispersar o polímero e o fármaco em um solvente ou sistema solvente, e atomizá-los via aspersor para originar microgotas que, ao entrarem em contato com o ar em temperatura próxima ou superior ao ponto de ebulição do solvente, proporcionam a evaporação do mesmo de forma rápida e dinâmica, formando as micropartículas (Fu et al., 2002, Silva-Júnior, 2005).

O estudo foi realizado de acordo com os princípios éticos na experimentação animal e foi aprovado pela Câmara de Ética em Experimentação Animal da Faculdade de Medicina Veterinária e Zootecnia da UNESP de Botucatu (Protocolo 113/2008 CEEA).

Foram utilizados 20 coelhos, de 2 a $3 \mathrm{~kg}$ da raça branca Neozelandesa, sadios e sem problemas oculares. Os animais foram distribuídos em quatro grupos $(\mathrm{G})$, utilizando-se apenas o olho esquerdo de cada animal: no G1, cinco animais induzidos à ceratite bacteriana experimental foram tratados por cinco dias com uma gota de solução salina básica (SSB), a cada seis horas; no G2, cinco animais com córnea sadia foram tratados com aplicação subconjuntival única de $0,2 \mathrm{~mL}$ contendo $2 \mathrm{mg}$ de ciprofloxacina e observados por cinco dias; no G3, cinco animais foram induzidos à ceratite bacteriana experimental e tratados por cinco dias com uma gota de ciprofloxacina $0,3 \%$, a cada seis horas; no $\mathrm{G} 4$, cinco animais foram induzidos à ceratite bacteriana experimental e tratados com aplicação subconjuntival única de $0,2 \mathrm{~mL}$ contendo $2 \mathrm{mg}$ de ciprofloxacina e observados por cinco dias.

Os animais foram anestesiados por meio da associação de acepromazina, $0,5 \mathrm{mg} / \mathrm{kg}$, xilazina, $5 \mathrm{mg} / \mathrm{kg}$, e ketamina, $35 \mathrm{mg} / \mathrm{kg}$, administradas por via intramuscular, e morfina, $3 \mathrm{mg} / \mathrm{kg}$, por via subcutânea, para os procedimentos de inoculação bacteriana intracorneana e aplicação da ciprofloxacina de liberação controlada. Colírio tópico de cloridrato de proximetacaína $0,5 \%$ foi utilizado como complemento anestésico.

Após antissepsia da superfície ocular com solução de iodo povidine diluída em solução fisiológica, procedeu-se à imobilização palpebral por meio de um blefaroestato Barraquere e à centralização do globo ocular com o auxílio de uma pinça de conjuntiva Bonn. A inoculação do $S$. aureus foi feita conforme a técnica descrita por Barequet et al. (2004), utilizando-se uma seringa Hamilton graduada em microlitros, com a introdução do bizel da agulha na periferia corneana até a profundidade estromal; esta foi, então, avançada até o centro da córnea, onde foram injetados $2,5 \mu \mathrm{L}$ do inóculo.

Todos os tratamentos tiveram início cinco horas após a inoculação intraestromal do S. aureus. A aplicação subconjuntival foi realizada no espaço subconjuntival utilizando-se uma agulha $13 \times 0,45 \mathrm{~mm}$ e seringa de $1 \mathrm{~mL}$, como descrito por Amrite et al. (2006).

As biópsias corneanas e os suabes da superfície ocular e do humor aquoso para análise da concentração de ciprofloxacina foram realizados logo após a eutanásia com pentobarbital sódico.

A colheita do material foi realizada com suabe estéril e por punch descartável estéril de $4 \mathrm{~mm}$. O suabe foi mantido em contato com a córnea e conjuntivas palpebrais por 20 segundos e, posteriormente, preservado em recipiente estéril até o seu processamento. $\mathrm{O}$ fragmento corneano foi mantido em um frasco estéril com solução salina para análise. A secreção ocular coletada por suabe e biópsia corneana foi processada em Laboratório Escola. As amostras foram semeadas em condições de aerobiose a $37^{\circ} \mathrm{C}$, em base de MacConkey e ágar sangue contendo $10 \%$ de sangue desfibrinado de ovelha, e observadas por 24, 48, 72 e 96 horas. O material que se apresentou com isolamento positivo teve seus agentes caracterizados macroscópica, microscópica (morfotinturial) e bioquimicamente, segundo Quinn et al. (1994).

Foram obtidos fragmentos por punch de $4 \mathrm{~mm}$ da espessura total da córnea, na região do inóculo bacteriano, e da conjuntiva, no local do depósito de PLGA de ciprofloxacina. Os coelhos do G2, não inoculados por $S$. aureus, foram biopsiados na região central da córnea, supostamente a mesma localização das biópsias nos animais dos outros grupos. Não foi realizada a coleta de material conjuntival em G1 e G3, em razão da ausência da medicação de liberação controlada. O material coletado foi mantido em formol $10 \%$ até o seu processamento. Os cortes histológicos foram fixados e depois corados por hematoxilina-eosina (HE). 


\section{RESULTADOS}

Todos os animais do G1 apresentaram extenso piogranuloma com infiltrado inflamatório polimorfonuclear intenso (Fig. 1). O epitélio corneano demonstrou perda de sua integridade, enquanto o estroma possuía separação entre as fibras de colágeno. Foi observada também necrose focal com presença de colônias bacterianas.

Os cortes histológicos da córnea dos coelhos do G2 não demonstraram sinais de alteração. As camadas corneanas encontravam-se íntegras, sem infiltrado inflamatório e perda de celularidade. A biópsia da região conjuntival bulbar, onde foi administrada a ciprofloxacina de liberação controlada, evidenciou um leve grau de inflamação com infiltrado polimorfonuclear, congestão dos vasos sanguíneos e afastamento entre as células estromais (edema) (Fig. 2). Não houve qualquer sinal de agressão às células caliciformes do epitélio conjuntival.

Todas as córneas dos animais do G3 apresentaram infiltrado inflamatório polimorfonuclear. Os cortes histológicos de dois dos animais demonstraram a presença de um extenso piogranuloma, com debris celulares, neutrófilos, monócitos, macrófagos, linfócitos e raras colônias bacterianas. Os demais três animais exibiram apenas um discreto infiltrado inflamatório polimorfonuclear estromal e raras colônias bacterianas.

A maioria dos animais do grupo G4 não apresentou alteração corneana; apenas um animal ainda possuía sinais de inflamação e infecção. Havia discreto infiltrado polimorfonuclear com colônias bacterianas focais, semelhante às alterações encontradas nos animais do grupo G3. As alterações encontradas no tecido conjuntival foram iguais às obtidas no grupo $\mathrm{G} 2$.

Os resultados dos suabes mostraram-se negativos para o cultivo de $S$. aureus em G2, G3 e G4, e apenas dois animais do G3 apresentaram resultados positivos. Os suabes estéreis coletados de todos os grupos mostraram bastante contaminação secundária (Tab. 1). Os resultados microbiológicos das biópsias corneanas estão representados na Tab. 1 e, assim como os suabes, demonstraram quase completa ausência da bactéria inoculada. Apenas um animal foi positivo para a presença de Staphylococcus aureus dos fragmentos corneanos no G1.

Tabela 1. Avaliação qualitativa do microbiológico de suabe e biópsia corneana no quinto dia de tratamento

\begin{tabular}{|c|c|c|c|}
\hline \multirow{2}{*}{ Grupo } & \multirow{2}{*}{ Animal } & \multicolumn{2}{|c|}{ Presença bacteriana } \\
\hline & & Suabe & Biópsia \\
\hline \multirow{5}{*}{ G1 } & 1 & Staphylococcus aureus & Staphylococcus spp. \\
\hline & 2 & Aspergillus spp. & Negativo \\
\hline & 3 & Aspergillus spp. & Negativo \\
\hline & 4 & Staphylococcus aureus & Staphylococcus aureus \\
\hline & 5 & Bacillus spp. & Bacillus spp. \\
\hline \multirow{5}{*}{$\mathrm{G} 2$} & $1 \mathrm{a}$ & Negativo & Negativo \\
\hline & $2 \mathrm{a}$ & Aspergillus spp. & Negativo \\
\hline & $3 a$ & Bacillus spp.e Staphylococcus spp. & Bacillus spp. \\
\hline & $4 a$ & Negativo & Negativo \\
\hline & $5 \mathrm{a}$ & Negativo & Negativo \\
\hline \multirow{5}{*}{ G3 } & $1 b$ & Negativo & Negativo \\
\hline & $2 b$ & Bacillus spp. & Negativo \\
\hline & $3 b$ & Aspergillus spp. & Aspergillus spp. \\
\hline & $4 b$ & Negativo & Negativo \\
\hline & $5 b$ & Negativo & Negativo \\
\hline \multirow{5}{*}{ G4 } & $1 \mathrm{c}$ & Negativo & Negativo \\
\hline & $2 \mathrm{c}$ & Negativo & Negativo \\
\hline & $3 c$ & Aspergillus spp. & Aspergillus spp. \\
\hline & $4 c$ & Negativo & Negativo \\
\hline & $5 c$ & Negativo & Negativo \\
\hline
\end{tabular}




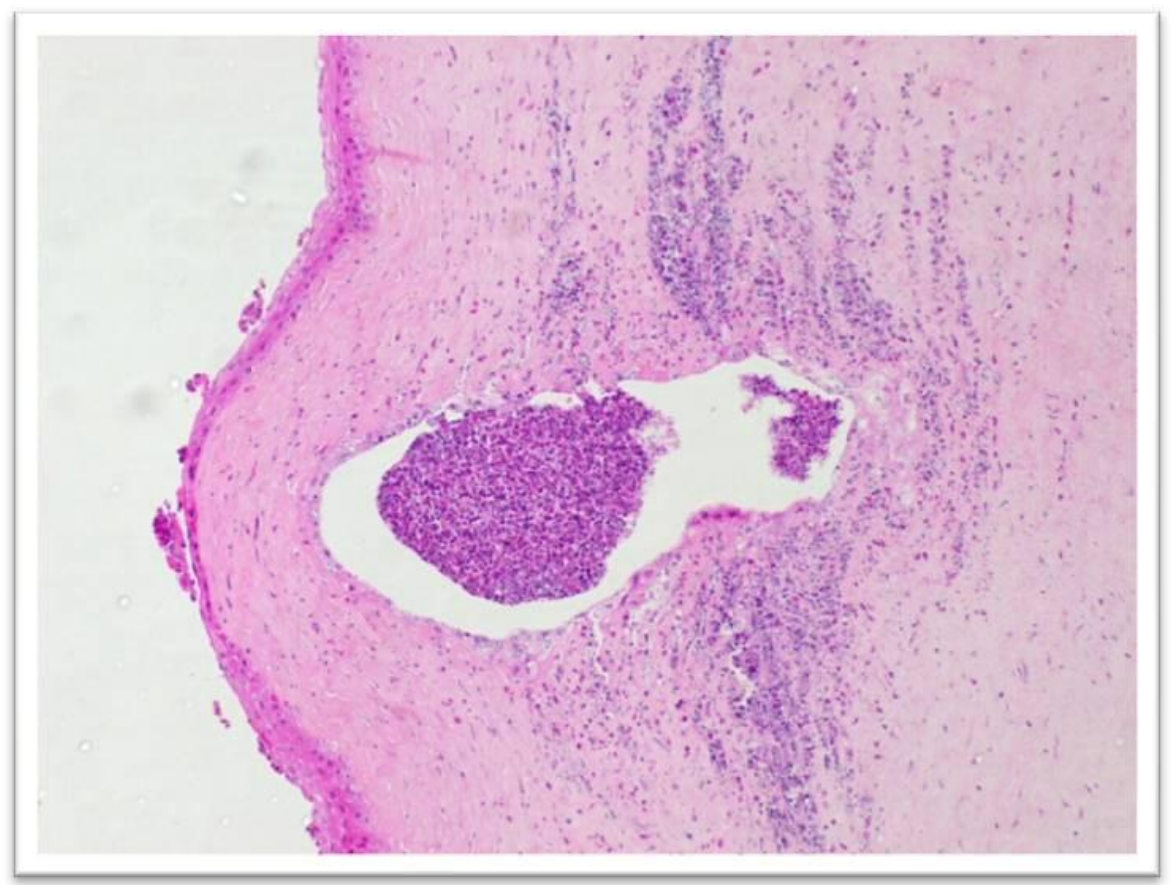

Figura 1. Corte histológico da córnea de coelhos induzidos à ceratite por Staphylococcus aureus e tratados com solução salina básica no quinto dia de experimento, visualizado com aumento de 10x. Presença de piogranuloma com grande quantidade de infiltrado polimorfonuclear e perda de células epiteliais.

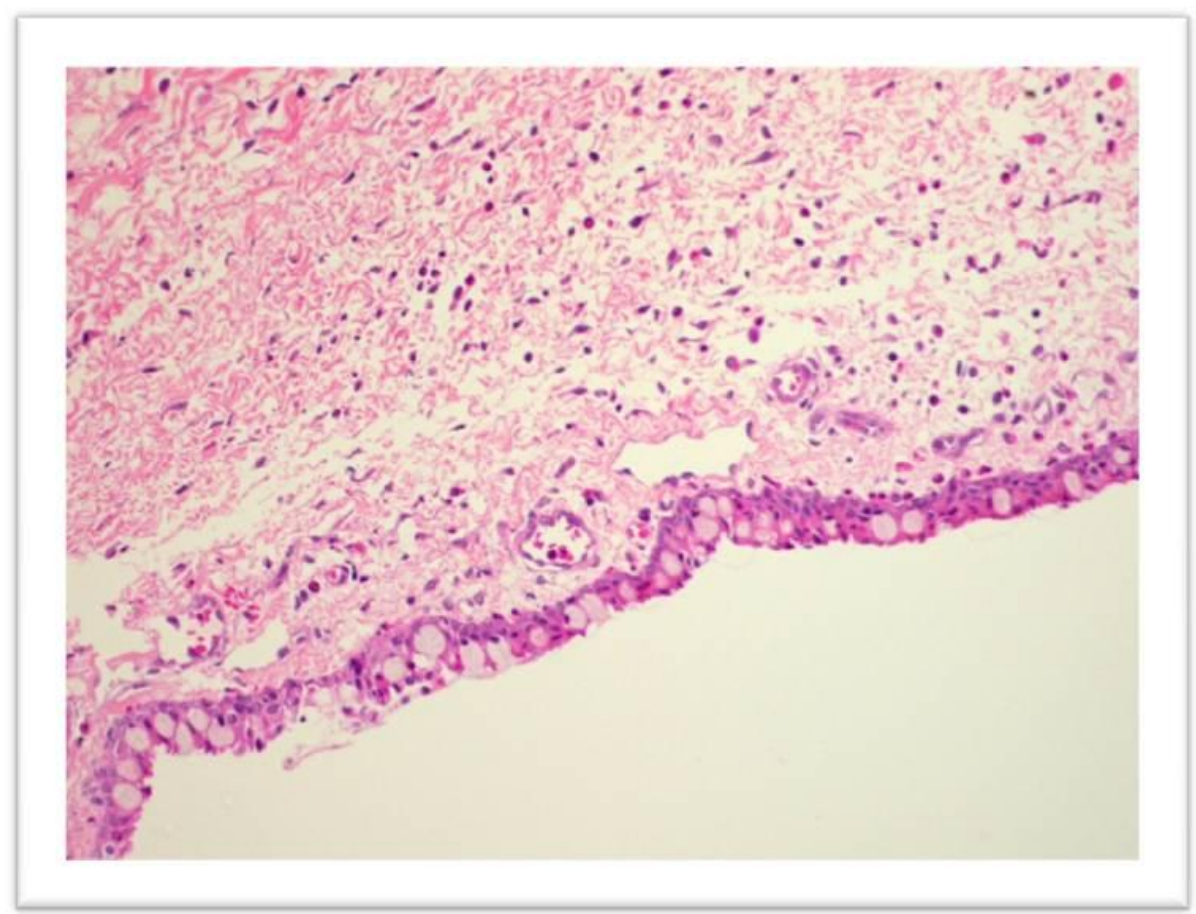

Figura 2. Corte histológico da conjuntiva de coelhos sadios tratados com aplicação subconjuntival única de $0,2 \mathrm{~mL}$ contendo $2 \mathrm{mg}$ de ciprofloxacina Nota-se uma moderada quantidade de infiltrado polimorfonuclear e separação entre as células estromais (edema). O epitélio conjuntival apresenta-se normal, com presença de células caliciformes. 


\section{DISCUSSÃO}

Os polímeros biodegradáveis podem apresentar vantagens sobre os não biodegradáveis, pois são totalmente absorvidos pelo organismo, não necessitando remoção subsequente e proporcionando melhor adesão e aceitação do paciente ao tratamento (Anderson e Shive, 1997; Fialho et al., 2003). No caso particular do PLGA, a degradação resulta nos ácidos lático e glicólico, que são compostos facilmente absorvidos pelo organismo (Husmann et al., 2002). Nos grupos G2 e G4, o polímero de PLGA diminuiu de volume do primeiro para o último dia de tratamento, evidenciando a sua capacidade biodegradável.

A resposta tecidual à injeção de micropartículas pode ser dividida em três fases. A primeira ocorre dentro das primeiras duas semanas, procedendo à injeção com iniciação, resolução e organização da resposta inflamatória aguda e crônica. Nas micropartículas biodegradáveis, esta resposta é similar, independentemente da taxa de degradação do polímero. Esta primeira fase também pode conter componentes da lesão mecânica causada pela agulha (Anderson e Shive, 1997); a segunda fase já é afetada pela taxa de degradação do polímero com a presença predominante de neutrófilos e macrófagos, que podem se fundir e formar células gigantes em resposta a corpos estranhos. Observa-se ainda formação da cápsula fibrosa e neoangiogênese, com a formação de vasos capilares ao redor do implante. Micropartículas contendo doses baixas de drogas podem passar por esta fase sem provocar a formação de cápsula fibrovascular; por fim, a terceira fase ocorre com a quebra da micropartículas em partículas menores, que são fagocitadas por macrófagos, completando a sua degradação (Anderson e Shive, 1997; Lima e Júnior, 1999).

No presente trabalho, a presença das micropartículas de PLGA carregadas com ciprofloxacina acabou originando um pequeno processo inflamatório localizado. Clinicamente observaram-se quemose e hiperemia conjuntival no local do implante. A presença de infiltrado polimorfonuclear na conjuntiva é um sinal claro de que o polímero não foi completamente inerte. O primeiro sinal de lesão ao epitélio conjuntival pode ocasionar um aumento do tamanho das células epiteliais e perda das células caliciformes, porém estas se mostraram preservadas no final do tratamento, deduzindo-se que a reação inflamatória não foi intensa $o$ suficiente a ponto de lhe causar lesões maiores (Kunert et al., 2002). Com cinco dias de experimento, a reação inflamatória permaneceu apenas na primeira fase; sendo assim, não houve a degradação completa das micropartículas que podiam ser observadas a olho nu. Amrite et al. (2006) relataram que micro e nanopartículas com $200 \mathrm{~nm}$ são quase completamente retidas na região periocular por pelo menos 60 dias.

Os resultados obtidos assemelham-se aos encontrados por Kimura et al. (1992), que, avaliando os efeitos perioculares de micropartículas de PLA em modelos experimentais com coelhos, observaram um pequeno processo inflamatório e tecido fibroso no local da administração uma semana após a injeção do sistema de velocidade controlada. Células gigantes multinucleadas foram responsáveis pela degradação e fagocitose das microesferas, sendo que a reação inflamatória ao corpo estranho diminuiu gradativamente até a $12^{\mathrm{a}}$ semana pós-administração, quando apenas resquícios das microesferas foram encontrados.

Saishin et al. (2003), entretanto, concluíram clinicamente que, após 10 e 20 dias da injeção periocular de micropartículas de PLGA-glicose em porcos, não houve sinais de infecção e inflamação. Amrite et al. (2006) chegaram a resultados semelhantes utilizando também o PLGA como polímero, nos quais observaram hiperemia ou edema no local da aplicação, enquanto histopatologicamente não houve a presença de células inflamatórias e formação de tecido fibroso, concluindo que isto se devia à natureza biodegradável do polímero. Já Lima e Júnior (1999), estudando polímeros de PLA e PLGA injetados no tecido subcutâneo de ratos, notaram que seis horas após a administração houve o começo do recrutamento celular e que micropartículas carreando drogas apresentaram uma reação inflamatória mais intensa do que a do polímero puro.

Pode-se considerar, então, que a presença da ciprofloxacina e a dose administrada dela podem ter contribuído para a reação inflamatória. Benjaafhar et al. (1995) testaram quatro doses de pefloxacina subconjuntival em coelhos $(0,8,1,6$, 8 e 16mg), e os resultados apresentados 
mostraram que as três dosagens mais altas causaram hemorragia conjuntival e quemose; apenas $0,8 \mathrm{mg}$ de pefloxacina foi bem tolerada pelo organismo clínica e histologicamente. Donnenfeld et al. (1997) descreveram que doses intravítreas de ciprofloxacina de $100 \mu \mathrm{g}$ são bem toleradas e que, acima disso, observa-se toxicidade corneana aguda em coelhos.

Embora Saishin et al. (2003) e Amrite et al. (2006) tenham relatado que o PLGA não causou qualquer sinal de inflamação, a sua degradação em ácido lático e glicólico aumenta a acidez local, podendo levar a reações inflamatórias por parte do organismo (Oliveira e Lima, 2006). A mudança do $\mathrm{pH}$ pode igualmente alterar as características do antibiótico aplicado, provocando reações indesejáveis. A solubilidade da ciprofloxacina permite que esta seja formulada com um $\mathrm{pH}$ de 4,5 (Donnenfeld et al., 1997). Satia et al. (2005) relataram que, ao entrar em contato com o filme lacrimal e consequente alteração do $\mathrm{pH}$, a ciprofloxacina pode precipitar-se, levando a uma reação local.

A ausência do $S$. aureus nas culturas realizadas comprovou a eficiência do tratamento tanto no grupo com o sistema de liberação controlada quanto no de terapia convencional à base de colírio. A contaminação secundária por Staphylococcus spp., Bacillus spp. e Aspergillus spp. pode ser considerada um achado normal, já que são microrganismos residentes da flora normal de coelhos. Cooper et al. (2001), ao observarem a flora normal de 70 coelhos sadios, encontraram Staphylococcus spp. em 57\% e Bacillus spp. em $19 \%$ dos animais estudados. O grupo controle bacteriano (G1) apresentou apenas um animal positivo para $S$. aureus no exame microbiológico, porém a histopatologia evidenciou a presença de um piogranuloma com poucas colônias bacterianas. Esta diferença entre os dois exames pode ter ocorrido pelo fato de as coletas microbiológicas não terem alcançado o local da infecção, tendo em vista que o organismo encapsulou a infecção, isolando-a a uma área restrita.

\section{CONCLUSÕES}

Verificou-se que o sistema de liberação controlada de PLGA foi eficiente no tratamento de ceratites bacterianas, eliminando por completo a presença do $S$. aurues do tecido corneano.
Entretanto, não se mostrou completamente biocompatível com a região subconjuntival. A manipulação mecânica e a presença de um fármaco podem ter sido os fatores principais causadores da resposta inflamatória. Nota-se também que as micropartículas testadas levam acima de cinco dias para serem completamente absorvidas pelo organismo.

\section{REFERÊNCIAS}

AMRITE, A.C.; AYALASOMAYALAJULA, S.P.; SHERUVU, N.P.S. et al. Single periocular injection of celecoxib-PLGA microparticles inhibits diabetesinduced elevations in retinal $\mathrm{PGE}_{2}, \mathrm{VEGF}$, and vascular leakage. Invest. Ophthalmol. Vis. Sci. v.47, p.1148-1160, 2006.

ANDERSON, M.J.; SHIVE, S.M. Biodegradation and biocompatibility of PLA and PLGA microspheres. Adv. Drug Deliv. Rev., v.28, p.5-24, 1997.

BAREQUET, I.S.; DENTON, P.; OSTERHOUT, G.J. et al. Treatment of experimental keratitis with topical trovafloxacin. Arch. Ophthalmol., v.122, p.65-69, 2004.

BENJAAFAR, S.M.; COCHEREAU, I.; D'HERMIES, F. et al. Tolerability, kinetics, and efficacy of subconjunctival pefloxacin in pigmented rabbits. Antimic. Agents Chemother., v.39, p.834-838, 1995.

BOURGES, J.L.; GAUTIER, S.E.; DELIE, F. et al. Ocular drug delivery targeting the retina and retinal pigment epithelium using polylactide nanoparticles. Invest. Ophthalmol. Vis. Sci., v.44, p.3562-3569, 2003.

COOPER, S.C.; McLELLAN, G.J.; RYCROFT, A.N. Conjunctival flora observed in 70 healthy domestic rabbits (Oryctolagus cuniculus). Vet. Rec., v,149, p.232-235, 2001.

DONNENFELD, E.D.; PERRY, H.D.; SNYDER, R.W. et al. Intracorneal, aqueous humor, and vitreous humor penetration of topical and oral ofloxacin. Arch. Ophthalmol., v.115, p.173-176, 1997.

DOWLING, P.M.; GRAHN, B.H. Antimicrobial therapy of ocular infections. Can. Vet. J., v.39, p.121123, 1998.

FIALHO, S.L.; REGO, M.G.B.; CARDILLO, J.A. et al. Implantes biodegradáveis destinados à administração intra-ocular. Arq. Bras. Oftalmol., v.66, p.891-896, 2003.

FU, Y.J.; SHYU, S.S.; SU, F.H. et al. Development of biodegradable co-poly (D,Llactic/glycolic acid) microspheres for the controlled release of 5-FU by the spray drying method. Colloids Surf. B: Biointerfaces, v. 25, p. $269-279,2002$. 
GELATT, K.N. Doenças e cirurgia da conjuntiva do cão. In:__. Manual de oftalmologia veterinária. São Paulo: Manole, 2000. cap.5, p.95-112.

GHELARDI, E.; TAVANTI, A.; DAVINI, P. et al. A mucoadhesive polymer extracted from tamarind seed improves the intraocular penetration and efficacy of rufloxacin in topical treatment of experimental bacterial keratitis. Antimicrob. Agents Chemother., v.48, p.3396-3401, 2004.

HUSMANN, M.; SCHENDERLEIN, S.; LUCK, M. et al. Polymer erosion in PLGA microparticles produced by phase separation method. Intern. J. Pharm., v.242, p.277-280, 2002.

KIMURA, H.; OGURA, Y.; MORITERA T. et al. Injectable microspheres with controlled drug release for glaucoma filtering surgery. Invest. Ophthalmol. Vis. Sci., v.33, p.3436-3441, 1992.

KOMPELLA, U.B.; BANDI, N.; AYALASOMAYAJULA, S.P. Subconjunctival nano- and microparticles sustain retinal delivery of budesonide, a corticosteroid capable of inhibiting VEGF expression. Invest. Ophthalmol. Vis. Sci., v.44, p.1192-1201, 2003.

KUNERT, K.S.; TISDALE, A.S.; GIPSON, I.K. Goblet cell numbers and epithelial proliferation in the conjunctiva of patients with dry eye syndrome treated with cyclosporine. Arch. Ophthalmol., v.120, p.330337, 2002.

LIMA, K.M.; JÚNIOR, J.M.R. Poly-DL-lactide-coglycolide microspheres as a controlled release antigen delivery system. Braz. J. Med. Biol. Res., v.32, p.171180, 1999.
McGHEE, C.N.J.; NIEDERER, R. Resisting susceptibility: bacterial keratitis and generations of antibiotics. Clin. Experiment. Ophthalmol., v.34, p.35, 2006.

OLIVEIRA, R.B.; LIMA, E.M. Polímeros na obtenção de sistemas de liberação de fármacos. Rev. Eletr. Farm., v.3, p.29-35, 2006.

PONTES, K.C.S.; BORGES, A.P.B.; DUARTE, T.S. et al. Membrana amniótica canina utilizada como bandagem em úlcera superficial de córnea de coelhos aspectos clínicos. Arq. Bras. Med. Vet. Zootec., v.60, p.1069-1074, 2008.

QUINN, P.J.; CARTER, M.E.; MARKEY, P. et al. In: Clinical veterinary microbiology. 1.ed. São Paulo: Mosby, 1994. 648p.

SAISHIN, Y.; SILVA, R.L.; SAISHIN, Y. et al. Periocular injection of microspheres containing PKC412 inhibits choroidal neovascularization in a porcine model. Invest. Ophthalmol. Vis. Sci., v.44, p.4989-4993, 2003.

SATIA, M.C.; MODY, V.D.; MODI, R.I. et al. Pharmacokinetics of topically applied sparfloxacin in rabbits. Indian J. Ophthalmol., v.53, p.177-81, 2005.

SILVA JUNIOR, A.A. Micropartículas biodegradáveis para liberação prolongada intraocular de fármacos. 2005. 140f. Dissertação (Mestrado em Ciências Farmacêuticas) - Faculdade de Ciências Farmacêuticas, Universidade Estadual Paulista, Araraquara, SP. 